\title{
Estados obstinados:
}

¿humanitarismo limitado?

la migración por asilo como

parte de las agendas de

seguridad estatal y su choque

con el régimen internacional de los derechos humanos

Mauricio Palma Gutiérrez

En el mundo, los gobiernos toman medidas de excepción en nombre de la seguridad. Cuando una amenaza surge y esta es tan extensa que puede poner en entredicho la supervivencia de la población o la integridad del Estado, parece válido limitar el ejercicio de derechos individuales a través de medidas que van desde pequeñas restricciones hasta suspensiones absolutas. Basta con mirar las determinaciones del gobierno Hollande en Francia luego de los atentados múltiples en París que dejaron más de 300 personas muertas en noviembre de 2015, las medidas de excepción tomadas el mismo año por varios gobiernos de África occidental, con ocasión del brote de Ébola que dejó otros tantos miles de muertos o las polémicas decisiones tomadas por los presidentes Erdogan y Maduro ante presuntos golpes de Estado en su contra en 2016. En todos los casos, con suficiencia de causa o no, derechos a la movilidad individual, a la protesta, a la libre expresión y otros más fueron restringidos, con la finalidad de mantener la calma y el orden. 
Sin embargo, con la amenaza también surge la tentación de limitar derechos, aunque no siempre sea necesario, o la tentación de dar una respuesta política a la crisis dejando de lado la garantía de los derechos. En ocasiones, la seguridad se convierte en el chivo expiatorio de muchos gobiernos, los cuales reafirman el control soberano de los Estados que representan y pueden dejar de cumplir con sus obligaciones, como en el caso del Régimen Internacional de los Derechos Humanos.

Este régimen internacional -o conjunto de principios, normas y reglas sobre los cuales convergen las expectativas de los actores internacionales en un determinado tema (Krasner, 1982) — está compuesto hoy por un sinfín de instrumentos jurídicos altamente legalizados, pero cuyo elemento central es a todas luces la Declaración Universal de los Derechos Humanos de 1948. Buena parte de los teóricos jurídicos consideran estos derechos como normas de ius cogens - naturales e inherentes a la existencia de los individuos-, los cuales deben ser garantizados a las personas, por todos los Estados del sistema, por el solo hecho de ser personas, dejando de lado diferencias basadas en nacionalidad, ciudadanía o estatus legal. En la actualidad, se entiende que luego de siglos de evolución normativa, los Estados son los principales responsables de hacer valer estos principios, más allá de las características particulares que cada individuo posee.

Así, los Estados occidentales luego del fin de la Segunda Guerra Mundial se encargaron de impulsar la defensa de estos derechos. Algunos lo hicieron no solo bajo la premisa de que manteniendo unos principios y valores mínimos se garantizaría la coexistencia pacífica de los individuos en el sistema; lo hicieron también como un mecanismo para intervenir en la política de Estados jóvenes y menos poderosos sin incurrir en un intervencionismo abierto, de esa manera se aumentaba la legitimidad de sus acciones. La política del buen vecino en América Latina, la idea de la Françafrique y más recientemente la política de buena vecindad europea son ejemplos de esto. Así, esta dinámica funcionó con relativo éxito durante la Guerra Fría, sobre todo en las zonas de influencia de occidente. Sin embargo, hoy por hoy, el discurso humanitario limita las acciones de sus impulsores originales, ante las respuestas estatales a fenómenos que han sido considerados como amenazas por sus gobiernos, en los cuales las libertades individuales 
parecen ser cooptadas en nombre de la seguridad. Este es el caso de la oleada actual de migración por asilo.

La migración por asilo es un flujo migratorio compuesto por personas que buscan desplazarse hacia un destino específico, con el fin de obtener allí el estatus de refugiado, cumpliendo o no con las condiciones jurídicas necesarias para acceder a este derecho. Dicho de otra forma, este flujo está integrado por personas que escapan de la violencia, la persecución religiosa o étnica —elementos definitorios para acceder al derecho de asilo consignados en la Convención al respecto de 1951-, así como por otras personas que migran buscando obtener este derecho sin cumplir necesariamente con lo establecido en la normativa internacional - lo que no implica que no necesiten de esta protección.

La crisis en Siria, las condiciones políticas en Afganistán, Eritrea y África subsahariana, la inseguridad en el triángulo norte centroamericano y la imprevisibilidad ante los cambios políticos en Cuba —entre muchos otros factores - han acentuado los flujos de migrantes por asilo en diferentes partes del mundo durante el último par de años. En Europa se habla de la "mayor crisis migratoria de la historia" (Koren, 2015) mientras que en Estados Unidos y Australia el tema ocupa las agendas políticas de gobernantes y opositores. Mientras tanto, la envergadura del fenómeno ha hecho que los Estados de destino y de tránsito de estas personas comiencen a catalogar el asunto como un tema de seguridad, ante lo cual se prevén medidas excepcionales, que ponen muchas veces en entredicho los derechos de aquellos que migran.

De manera, tomando el ejemplo de la migración por asilo, este capítulo describe cómo los Estados, apegados a su capacidad de control soberano, privilegian medidas de excepción ante fenómenos que son calificados como amenazas por sus gobiernos, en detrimento del régimen internacional de los Derechos Humanos. Así, muchos Estados, como los europeos, parecen obstinarse en mantener su control soberano ante dinámicas de envergadura transnacional incurriendo en lo que parece ser una paradoja: la legitimidad que han ganado durante años como defensores del esquema internacional de derechos se desborona ante la premura por tomar acciones soberanas, en pro de neutralizar fenómenos percibidos como amenazas a su seguridad. 
Para darle peso a esta idea, este capítulo se divide en cuatro partes. En la primera se hace una aproximación crítica al estado actual del Régimen Internacional de Derechos Humanos ante la idea de soberanía, central aún en el entendimiento del sistema moderno internacional. En la segunda sección se establece el marco de análisis de la migración por asilo como fenómeno que ejemplifica el choque entre seguridad, control soberano y régimen internacional. En la tercera parte se ofrece como ejemplo la crisis de la migración por asilo a través del Mediterráneo para mostrar el choque entre control soberano y derechos humanos. Por último, se ofrecen las conclusiones del capítulo.

\section{Control soberano y derechos humanos: dinámicas prevalentes, dinámicas en evolución}

La idea de derechos humanos ha venido evolucionando conforme las dinámicas del sistema internacional lo han hecho. La aspiración por igualdad y libertad entre seres humanos es antigua y responde no solo a la voluntad filantrópica de algunos seres excepcionales sino también a profundos intereses políticos. En América hispana, por ejemplo, pensar en los indígenas como personas respondía a una lógica económica particular, así como lo fue el movimiento abolicionista británico en contra de la esclavitud, de fines del siglo XVIII y comienzos del siglo XIX (Williams, 2011). Lo mismo se puede decir del interés de los revolucionarios franceses en 1789 al declarar los Derechos del Hombre, quienes no buscaban sino romper con la estructura monárquica de la época en favor de una nueva élite, que distaría de proteger la idea de libertad e igualdad absolutas.

En el caso de la Declaración de los Derechos Humanos de 1948 — piedra angular del régimen que hoy lleva su nombre-, los intereses políticos también fueron evidentes. La Asamblea General de la ONU, que proclamó estos derechos como un ideal común de todos los pueblos y naciones, distaba de ser el actual compendio de 193 entidades cultural y políticamente distantes. En ese entonces, el compendio de treinta artículos que constituyen la declaración era más un recetario 
en contra de las aspiraciones imperiales de unos, como los europeos occidentales que renunciaban ya a sus posesiones en África y Asia, y ante la expansión ideológica de otros, como los soviéticos quienes buscaban formalizar su esfera de influencia en Europa central y oriental. No obstante, desde el puro nivel jurídico, la aparición de esta declaración implicó obligaciones formales por parte de los Estados, los llamados a defender estos derechos, ante las personas, que dejaron de ser formalmente sujetos para convertirse en individuos.

A partir de entonces es posible hablar de un buen número de instrumentos jurídicos que han venido apareciendo, fortaleciendo la declaración original y ensanchando el espectro de lo que hoy se conoce como derechos humanos. Es posible hablar de pactos de derechos civiles y políticos (de la década de los sesenta), de convenciones en contra del genocidio (1948) y de la tortura (1987), de pactos específicos sobre los derechos de la mujer y la niñez y de muchos otros subcapítulos en materia de derechos humanos. Al tiempo, y muy de la mano del trabajo de la Organización de Naciones Unidas (ONU) y su Consejo de Derechos Humanos, han surgido diferentes agencias especializadas encargadas de velar por la correcta aplicación de estos instrumentos, como ONU Mujeres, Unicef y Acnur, entre muchas otras, así como organizaciones intergubernamentales por fuera del esquema de la ONU - pero en constante trabajo con esta- como la Organización Internacional para las Migraciones (OIM), por solo mencionar una.

También surgieron a lo largo del siglo XX diferentes manifestaciones de la sociedad civil organizada que buscaban impulsar esta dinámica de derechos. Quizá, la más conocida de estas organizaciones, aunque no la única, es Human Rights Watch. Todos estos mecanismos, entre intergubernamentales y no gubernamentales, de la mano de los instrumentos normativos existentes, configuran el actual régimen. Sin embargo, aunque extenso por la naturaleza de sus dinámicas y amparado en las acciones de un número indefinido de actores que lo defienden, este régimen cuenta con una limitación inherente a su existencia. En últimas, su aplicación depende de las decisiones de los Estados, actores soberanos y autónomos del sistema, y no del entramado de otros actores que defienden el régimen. Estos, si bien pueden influir e incluso coaccionar a las entidades estatales, no pueden intervenir de 
manera abierta, de acuerdo con el Principio de No Intervención consignado en el artículo 2 de la Carta de San Francisco, piedra angular del sistema de la ONU.

En torno a la aplicación y el desarrollo del Régimen Internacional de los Derechos Humanos, los Estados son jueces y partes, por cuanto sus gobiernos son los que negocian por medio de convenciones, foros y, por supuesto, mediante el ente más intergubernamental de todos, la ONU, el alcance de estas normas. Al tiempo, estos son los que tienen en la práctica la autonomía y la discreción de aplicarlos o no, o de implementarlos a su conveniencia dentro de sus fronteras, pese a que estos derechos se suponen inherentes a la existencia de los seres humanos. Esto se traduce en que, en la práctica, su aplicación está en manos de entidades soberanas y el entorno internacional cuenta con capacidades de intervención limitadas, solo determinadas por las dinámicas de poder sistémicas — como mediante sanciones políticas o económicas o intervenciones militares amparadas por el Consejo de Seguridad, tal y como sucedió en Libia en 2011.

Esto no significa que los Estados sean necesariamente actores taimados que negocian con otros únicamente buscando la maximización de su interés nacional, como aseguraría el realismo más acérrimo. Algunos Estados estiman que los derechos humanos son mecanismos regulatorios loables, los cuales deben ser profundizados, como elementos que apoyan la construcción de estabilidad en el sistema. En cualquier caso, la ejecución del esquema normativo depende, en últimas, de estas entidades, que pueden apelar en cualquier momento a su autoridad soberana respetada y proclamada como una de las reglas mínimas sobre las que se estructura el sistema internacional moderno.

De esa manera se hace evidente que la delegación a un tercer ente, más allá de los Estados, dentro del Régimen Internacional de los Derechos Humanos es mínima. ${ }^{1}$ Dicho de otra forma, la capacidad de control soberano de los Estados prevalece en la práctica ante estos

1 Abbott et al. (2000) consideran que la delegación de una norma internacional - relativo a la existencia de un ente encargado específicamente de velar por la implementación de esta- es uno de los tres criterios que determinan el grado de institucionalización de una norma. 
mecanismos normativos que han sido impulsados en el entorno internacional por diferentes actores con agendas específicas. Sobre esto es necesario anotar que los actores que impulsaron la idea de derechos humanos, como mecanismos regulatorios del sistema a finales de la década de los años cuarenta fueron aquellos que tenían la voluntad de utilizarlos como elementos de poder blando en diferentes locaciones, más aún, en medio de las dinámicas de la Guerra Fría.

Entonces, la idea de libertad e igualdad era fomentada desde Occidente como parte del recetario para la estabilidad y el progreso, que se anteponía al autoritarismo que se asociaba con los regímenes socialistas, como el soviético. La idea de derechos humanos, de estirpe liberal, buscaba atraer a aquellos Estados jóvenes que apenas comenzaban con su vida independiente en África y en Asia, así como servían para abrir capítulos regionales de entendimiento con los vecinos del hemisferio Occidental, con quienes los Estados Unidos, por ejemplo, concretaron la creación de una Comisión Interamericana de Derechos Humanos y una corte intergubernamental en este respecto.

Aunque esta estrategia política tuvo un relativo éxito, sobre todo en el momento de la implosión soviética y la desarticulación de los regímenes socialistas que esta apoyaba, un efecto boomerang comenzó a hacerse manifiesto en la década de los noventa. Por una parte, los derechos humanos comenzaron a ser contestados desde diferentes puntos del mundo no occidental, al ser entendidos por muchos como extensiones del discurso de control político de las potencias del sistema. En esta década, se desarrollaron conflictos como los de Rwanda y la antigua Yugoslavia y en la oleada terrorista de Al Qaeda, en Nairobi y Dar es Salaam — por solo mencionar dos ejemplos-, con lo cual se mostró la deshumanización de las acciones, por lo tanto, el discurso estaba lejos de ser entendido como verdaderamente universal.

Mientras tanto, estos derechos comenzaron a ser exigidos de manera masiva por actores no convencionales en algunos países occidentales, con ocasión del surgimiento de fenómenos transnacionales, que no se habían manifestado anteriormente en estos Estados. Uno de ellos puso de relieve cómo naciones, en principio impulsores del régimen, pueden entrar en la disyuntiva de hacer valer su control soberano ante la limitación de los derechos, teniendo como chivo expiatorio le 
definición de una amenaza. Este se encabeza por los procesos de migración por asilo masivos hacia Estados Unidos, Europa y Australia que desde la década de los noventa se han mantenido dentro de las agendas de estos actores como asuntos de seguridad.

\section{Derecho de asilo y refugio: a medio camino en el debate por el control soberano}

Como se comentó anteriormente, la migración por asilo es un flujo migratorio particular, compuesto por personas que se desplazan a través de fronteras internacionales con el fin de solicitar asilo en un Estado de destino determinado y así hacerse con el derecho de permanencia bajo la figura del refugio. Aunque su evolución puede trazarse por siglos, esta figura jurídica se formalizó luego de la Segunda Guerra Mundial mediante la Convención de Ginebra de 1951 —en medio del espíritu del nunca más a la guerra en Europa continental (McConnachie, 2014). En 1967, por medio del Protocolo Adicional a la Convención, la figura del asilo se extendió globalmente, hasta ser hoy un compromiso adquirido por buena parte de los Estados en el sistema. ${ }^{2}$

Ahora bien, la forma más común para denominar a aquellas personas que han adquirido este derecho ante un Estado determinado es la de refugiado. En la práctica, este término es equivalente al de asila$d o$; en el hemisferio occidental esta terminología se confunde con la figura del asilo político, la cual fue una categoría de derecho creada en medio del periodo de dictaduras en América Latina y que se basa en una serie de tratados bilaterales entre los Estados de la región. Su propósito de base fue garantizar condiciones de supervivencia mínima a opositores políticos y disidentes de los regímenes autoritarios que entonces se configuraron. De cualquier forma, en este texto se utilizan los términos refugiado y asilado de manera equivalente.

Hoy la migración por asilo se ha convertido en una categoría de análisis político por sí sola. Su evolución se puede trazar a partir de

2 A agosto de 2016 había 142 Estados parte de los dos instrumentos (Acnur, 2016a). 
limitaciones jurídicas que distan aún de ser resueltas y que, a la larga, describen el choque entre la autoridad soberana de los Estados y los instrumentos de derechos humanos existentes. Un ejemplo de ello es la forma como se adquiere el derecho de refugio. Para obtener asilo en un Estado determinado ahora difícilmente se pueden dejar de lado los canales de migración irregulares. Muchas naciones dejaron de admitir solicitudes asilo en sus embajadas desde finales de los años setenta, al prever que las crisis políticas en lugares tan disímiles como Irán, Afganistán, Angola o Yugoslavia llevarían a una oleada de solicitudes imprevistas. Hoy en día para obtener el derecho de asilo, la persona que quiera hacerse con este debe solicitarlo una vez haya llegado al país de destino, lo cual produce que muchas veces, los migrantes deban entrar de manera irregular al país de destino o sobrepasen los términos de su estatus migratorio, por ejemplo, no respetando las fechas de sus visados.

De esta forma, muchos solicitantes de asilo prefieren ingresar a un Estado de manera irregular o permanecer en un lugar de destino sin la documentación válida para hacerlo, antes que quedarse o devolverse a aquellos lugares en los que su vida estaría presuntamente en peligro. De allí que la demanda por traficantes se mantenga constante, al ser estos agentes de paso que, en la práctica, reducen los costos de transacción de los buscadores de asilo, quienes la gran mayoría del tiempo ingresan en su Estado de destino - y transitan por otros cuantos- como migrantes indocumentados, o irregulares.

Además, probar quién es o no es un solicitante de asilo que se acoge a las reglas de la Convención de Ginebra es un proceso arduo. Desde el puro nivel jurídico, este proceso se basa en la buena fe, como principio general del derecho. En la práctica, este se centra más en la presunción; muchas de las personas que escapan de condiciones desfavorables en sus lugares de origen a razón de su militancia política o su pertenencia étnica o racial deben declarar ante las autoridades en destino cuáles son las razones de su migración, sin tener los documentos que prueben su proveniencia, al haber muchas veces accedido a canales irregulares de migración, o a razón de la premura del tiempo que los forzó a dejar atrás sus documentos de viaje. En esto, los Estados 
están llamados a presumir la buena fe de las personas que solicitan hacerse con el derecho y, sobre todo, a darles un tratamiento diferencial.

Sin embargo, muchas personas que no necesariamente se acogen a los criterios consignados en las reglas de Ginebra, que definen la naturaleza de los flujos migratorios forzados y que desean migrar por otras razones (persecución por su orientación sexual, condiciones climáticas o desigualdades económicas, entre muchas otras) también han buscado acceder al derecho de asilo. Pese a que estas no se acogen en pleno sentido a los parámetros de la Convención, muchos individuos prefieren hacerse pasar por tales. Para estas personas, el horizonte de obtener el estatus de refugiado es una acción mucho más rentable que buscar acceder a la migración por otros canales, regulares, en medio de crecientes restricciones a la migración libre.

Así, la posibilidad de obtener el permiso de estadía mediante estos canales es mucho más alta que si lo buscaran por medio de mecanismos oficiales. Esto en la práctica ha generado dudas sobre la legitimidad de los buscadores de asilo que han llegado a diferentes destinos en los últimos tiempos. Lo anterior se basa en buena medida en pensar la migración internacional bajo el esquema imperante, como el resultado de una decisión que puede ser forzada o libre, lo cual crea una dicotomía que está en el origen de la teoría sobre flujos migratorios internacionales. La migración por asilo se inscribe así a mitad de camino entre lo uno y lo otro. La siguiente figura muestra cómo este flujo migratorio se inserta en los estudios sobre migración internacional dentro de la dualidad antes expuesta. 
Figura 1. Migración libre vs migración forzada

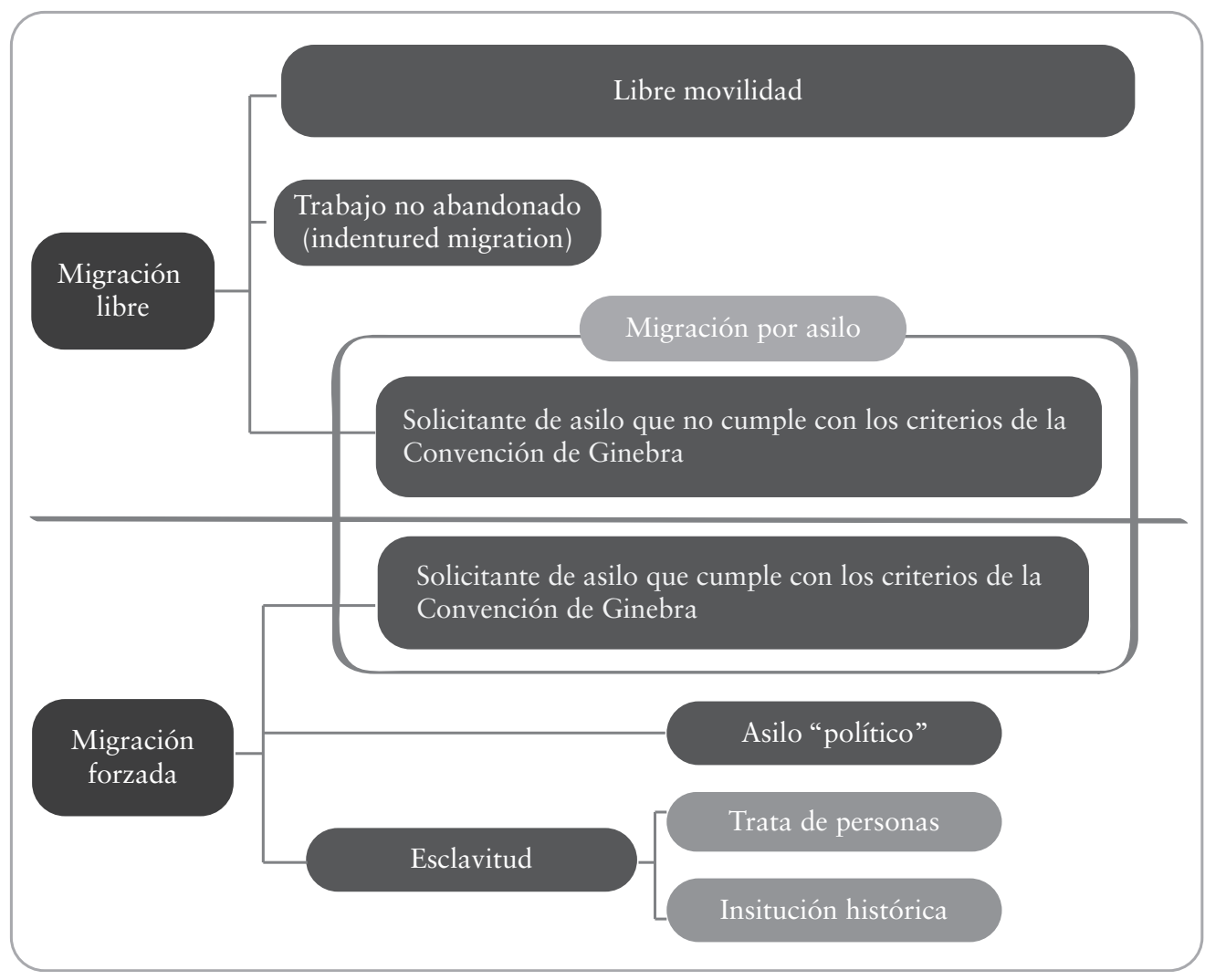

Fuente: elaboración propia.

Sin embargo, esta dicotomía entre migración libre y forzada ha sido revaluada por varios autores (Bretell y Hollifield, 2015; de Haas, 2014) al asumir que ningún flujo migratorio es totalmente forzado o totalmente libre, por lo cual se ha hecho un llamado constante a rediseñar las bases del debate teórico. Más aún, pese a que la migración por asilo ha hecho parte de las dinámicas del sistema internacional desde hace varias décadas (Bade, 2003), esta no se convirtió en un fenómeno dentro de las agendas de seguridad de los Estados sino hasta los años noventa. 
En lo anterior tuvieron que ver por lo menos tres fenómenos que coincidieron entre sí. El primero fue el fin de los regímenes autoritarios de Europa central y del este que implicó la movilización masiva de personas hacia Estados en Norteamérica y Europa occidental, y que entraron como solicitantes de asilo. El segundo fue el despertar de fuerzas políticas dentro de estos países que comenzaron a percibir los flujos migratorios masivos como eventuales amenazas a la estabilidad laboral, económica y social de sus poblaciones. El tercero fue la asociación que se ha hecho entre migración y terrorismo luego del 11 de septiembre de 2001 y de los atentados en Madrid y Londres de 2004 y 2005 , respectivamente. En medio de esta dinámica, la disyuntiva entre la capacidad soberana de los Estados para controlar la migración por asilo y el compromiso de defender los derechos de aquellos que estuviesen solicitando este derecho comenzó a hacerse evidente.

Luego de que la migración por asilo fuera puesta en la agenda de seguridad de los Estados, la posición fuerte de algunos de ellos y ante todo su voluntad de permanecer a cargo de las dinámicas soberanas a través de sus fronteras se ha manifestado en varias acciones para regular la migración por asilo. Se han dispuesto centros de acogida y de procesamiento de solicitudes de asilo en los lugares de mayor concentración de los flujos migratorios, como en Lesbos (Grecia), Lampedusa (Italia), Kiribati (en el Pacífico y a nombre de Australia) o a lo largo de la frontera mexicano-estadounidense, que algunos han calificado de centros de reclusión (Moloney, 2013).

También se han establecido reglas específicas de aceptación, como la regla del tercer Estado seguro que hace parte del reglamento europeo sobre asilo y refugio, o reglamento de Dublin. Esta establece que a cualquier solicitante de asilo que haya transitado por un Estado que sea considerado por la Unión Europea como un Estado seguro para obtener asilo, derivado de sus condiciones políticas y de seguridad, le será negado el derecho de asilo en territorio europeo y será devuelto al Estado de ingreso. Muchas veces estos mecanismos pueden rayar con el no cumplimiento del principio de Non-refoulement, consignado en la Convención de Ginebra. Por medio de este los Estados que hicieron parte de la Convención de Ginebra se comprometen a no devolver a 
su lugar de origen a una persona cuya solicitud de asilo haya sido rechazada y cuya supervivencia pueda estar en peligro. ${ }^{3}$

Sin embargo, estos Estados no son simples gamberros al momento de tomar este tipo de acciones. El compendio de normas que articulan el derecho a la movilidad dentro de la Declaración Universal de los Derechos Humanos establece que "toda persona tiene derecho a circular libremente y a elegir su residencia en el territorio de un Estado" (ONU, 2016), pero en ningún momento se establece que terceros Estados, de los cuales estas personas no sean nacionales, tengan la obligación de dejarles residir en él. A lo que se comprometen estos Estados mediante esta misma declaración es garantizar la vida de estos individuos dentro de un marco de dignidad y libre ejercicio de la conciencia. De allí que las acciones emprendidas por la Agencia de los Refugiados de la ONU (Acnur), la Organización Internacional de las Migraciones (OIM) o por parte de organizaciones que hacen parte de la sociedad civil organizada, solo pueden velar por el cumplimiento de estos estándares mínimos, exhortar al cumplimento de lo acordado, pero no forzar a los Estados a hacerlo. Lo anterior refleja que la capacidad soberana de los Estados en medio de este régimen sigue siendo un elemento constante y definitorio dentro de la dinámica internacional, pese a la existencia de elementos que parecen ser cada vez más transnacionales.

En medio de la voluntad de permanecer fuertes y al mando de las dinámicas territoriales, muchos Estados en Occidente atraviesan por disyuntivas en relación con la gestión de la migración por asilo y su compromiso con los derechos humanos. Así, sus propias acciones, por paradójico que parezca, han servido para aumentar la conciencia internacional sobre su falta de compromiso ante el cumplimiento de este régimen, otrora defendido de manera selectiva y según su conveniencia. La obstinación de los Estados de destino por mantener el control

3 Según Acnur (2016b), este principio — que en español se traduce como no devolución se establece en el artículo 33 de la Convención de Ginebra y hoy constituye una parte integral del derecho de refugio y asilo. No obstante, la definición política de este dista aún de ser consensuada por los Estados firmantes de la Convención. 
soberano sobre los flujos de migrantes por asilo ha servido para que estos mismos sean señalados por diferentes sectores como actores que instrumentalizan el régimen internacional de los derechos humanos a su conveniencia, trayendo consigo la erosión del discurso humanista como recurso de acción y con ello la afectación de su legitimidad. Esto se ejemplificará a continuación por medio del modelo de la migración por asilo a través del Mediterráneo.

\section{Migrantes por asilo y autoridad soberana en Europa: Estados obstinados, humanitarismo limitado}

En la actualidad, no son pocos los flujos de migración por asilo que tienen lugar a escala global. Uno de los más sonados en los últimos tiempos se desarrolla a través del Mar Mediterráneo, se origina en el Levante y el norte de África y tiene como destino Europa occidental. Este flujo ha servido como pretexto para que buena parte de los Estados europeos de destino de los migrantes, así como la misma Comisión Europea hayan comenzado a tomar medidas de excepción, basados en la presunta amenaza a la estabilidad que este flujo puede producir. Hasta agosto de 2016, las medidas tomadas lejos de solucionar de raíz el asunto, habían despertado serios cuestionamientos sobre el respeto de estos entes a los derechos de los migrantes, lo cual acarrea costos a su legitimidad como actores que dicen defender la aplicación de la carta de derechos.

Desde finales de 2011, la migración de buscadores de asilo a través del Mediterráneo y con destino Europa ha venido aumentando (Wihtol de Wenden et al., 2015). El pico migratorio de 2015 -más de 1.2 millones de solicitudes asilo en los Estados parte de la Unión Europea- solo confirmó la evolución de un fenómeno que venía cocinándose desde hacía varios años (Eurostat, 2016). Una de las razones más comentadas por los analistas para explicar este fenómeno apela a abordarlo como una de las consecuencias de la (inacabada) Primavera Árabe en varios Estados del Levante y el norte de África. Sin duda, hay una correlación entre la evolución de las hostilidades en Siria en 
el marco de su guerra civil, el arribo de Daesh como amenaza a la estabilidad de la región y la ausencia de un acuerdo entre las grandes potencias del sistema para darle una solución duradera al conflicto, y la cantidad de migrantes por asilo provenientes de la región. En su camino a Europa varios millones — casi tres según cifras recientes de Acnur (2016c)—, se han quedado en Turquía. Sin embargo, las islas griegas sobre el Peloponeso también se han convertido en lugares de recepción de los buscadores de asilo así como, tristemente, en cementerios a cielo abierto de aquellos que no han logrado llegar.

No obstante, este no es el único lugar de origen. Muchos de los actuales buscadores de asilo que tienen como destino Europa occidental son personas provenientes del Magreb y de África subsahariana, que encontraron en Libia un lugar de embarque ideal. Luego de la deposición de Al-Gaddafi en 2011, el país entró en un estado de ingobernabilidad del cual se han aprovechado milicias locales, sectores afines a Al Qaeda y Daesh y, por supuesto, mafias locales, para dividirse el país en esferas de influencia. Este clima de ingobernabilidad se ha vuelto propicio para que un sinnúmero de traficantes de migrantes haya establecido un lugar de embarque hacia Europa en las costas libias, para miles de migrantes que desde Eritrea, Ghana, Nigeria, e incluso Túnez y Marruecos atraviesan el desierto y siguen su camino hacia Europa (Gaffey, 2016).

Lo paradójico para los europeos es que mientras que Al-Gaddafi estuvo en el poder, aunque los incentivos para migrar de subsaharianos y magrebíes ya existían, su gobierno mantuvo el flujo controlado. Varios autores apelan a que una de las grandes consecuencias de la intervención en Libia auspiciada por los Estados europeos mediante la OTAN ha sido el arribo de miles de migrantes a las costas europeas, en medio de la crisis humanitaria que esta ha implicado (Fulton, 2015). Otros individuos, afganos, rohinyas y de Asia Central, también hacen parte del flujo de migrantes por asilo, derivado del estado de persecución que viven en sus lugares de origen.

Ante el arribo masivo de migrantes, las fuerzas políticas domésticas en Europa se han comenzado a polarizar en torno al debate sobre los buscadores de asilo. Si bien el asunto migratorio lleva años en la agenda de los Estados europeos — desde la década de los años setenta, con 
ocasión de la crisis financiera internacional y la contracción del mercado laboral europeo- (Castles et al., 2013), su relación como asunto de seguridad hoy ha tenido un efecto especial en los últimos años. Una reacción generalizada ha sido la apropiación del discurso antimigratorio por parte de fuerzas políticas no tradicionales, muchas de ellas de extrema derecha, quienes han encontrado tanto en el argumento económico como el cultural y el de criminalidad la excusa perfecta para poner los flujos migratorios al servicio de sus objetivos electorales.

Fenómenos como Orbán en Hungría, el partido Ley y Justicia en Polonia, el repunte del Partido Popular austriaco, el espacio político ganado por el Frente Nacional francés, el pro-Brexit UKIP británico y la Alternativa para Alemania(AfD) no se podrían explicar sin la crisis económica de finales de la década pasada y, ante todo, el asunto migratorio actual. Lo más interesante es que en medio de las presiones internas canalizadas por estas fuerzas políticas, muchos gobernantes europeos comenzaron a pensar en medidas de excepción que chocan con la estructura de derechos de los migrantes, con el fin de mantener la estabilidad en sus países. En esto ha sido necesaria la acción conjunta por medio del marco intergubernamental del Consejo Europeo y por supuesto el aval de la Comisión.

Para entender la evolución reciente de estas fuerzas es necesario tener en cuenta cómo se ha desarrollado el asunto migratorio. Desde 2012, se trazaba ya el aumento de los flujos de migrantes por asilo hacia Europa (ONU, 2015). Con los primeros naufragios y la situación humanitaria que se comenzó a gestar alrededor de la isla italiana de Lampedusa, se pusieron en marcha diferentes medidas para su gestión. Una fue la misión de vigilancia italiana Mare Nostrum (2013) en contra del tráfico de migrantes, la cual buscaba disminuir la escala del desastre humanitario que se comenzaba a desplegar sobre el Mediterráneo desde las costas de Libia. Al poco tiempo, la agencia europea para las fronteras externas, Frontex, tomó la vocería de la vigilancia sobre el mar europeo con la misión Tritón (2014). Además, en Italia y otros países se comenzaron a organizar centros de acogida para los migrantes en los cuales estas personas pudieran comenzar con sus aplicaciones de asilo, pero que también contaban con el propósito de mantener el control sobre los movimientos migratorios de estas personas, que 
muchas veces, sólo estimaban Lampedusa y Sicilia como un punto de paso hacia Alemania, Escandinavia y el Reino Unido. Sin embargo, estas medidas distaban de ser algo más que paliativos ante un fenómeno que se masificaba con la apertura de la denominada ruta mediterránea orienta hacia Europa desde Siria a través de Turquía.

Esta ruta comenzó a tomar forma mientras que el conflicto en Siria escalaba y Daesh ganaba posiciones en terreno. Aunque al principio de la confrontación muchos de los sirios que se encontraron en la mitad del fuego de las fuerzas beligerantes lograron asentarse en las vecinas Turquía, Jordania y Líbano, Europa se convirtió en el objetivo central. La promesa de trabajo y un mejor futuro fueron las consignas que hicieron de países como Suecia, Reino Unido y sobre todo Alemania los lugares prometidos para estas personas. El resultado fue la politización del asunto, hasta llegar a ser una de las principales preocupaciones del electorado en buena parte de los Estados europeos.

Ante esto gobiernos como el húngaro decidieron cerrar el paso a los migrantes que atravesaban los Balcanes con destino Europa occidental, mientras que diferentes movimientos que veían en la inmigración masiva una amenaza a la sostenibilidad el proyecto político europeo — como Pegida en Alemania- ${ }^{4}$ tomaban cada vez más fuerza. Los principales gobiernos de Europa representados en la estructura institucional de la Unión Europea se encontraban así frente a una disyuntiva. Por una parte, algunos pensaban en defender la Europa de las libertades y los derechos que se había constituido durante años en el destino imaginado de aquellos que eran perseguidos por la guerra, los regímenes autoritarios y la crueldad de la violencia. Por otra parte, los problemas en la construcción de la Europa de los 28, que alguna vez se intentó pensar como algo más que un bloque comercial, saltaban de nuevo a la vista. Sus gobernantes se encontraban una vez más frente a las limitaciones de la creación de una posición conjunta ante un problema cada vez más transnacional y que esta vez se definía en torno a un asunto prevalentemente humanitario.

4 Acrónimo de Patriotas Europeos en Contra de la Islamización de Occidente. 
Así, los gobernantes de las principales potencias europeas, con Angela Merkel a la cabeza, impulsaron un paquete de medidas para frenar la migración por asilo con unos objetivos políticos en mente. Se pensó en frenar el proceso de disgregación europeo interno, que desde Europa central y oriental había comenzado a contagiar a los electores de las potencias de Europa occidental. El cerramiento húngaro de las fronteras, y las posiciones intransigentes de eslovacos y polacos con respecto a la migración por asilo debían ser contenidos antes de que hicieran eco en los votantes de otros países. Por otro lado, las limitaciones físicas de Europa para recibir la oleada de migración masiva se habían convertido en un problema, ante la inexistencia de un reparto equitativo de cargas fiscales y de solicitantes de asilo. ${ }^{5}$

Mientras tanto el problema humanitario seguía creciendo y se comenzaban a reportar cada vez más vejámenes en contra de los buscadores de asilo en los centros de recepción, así como a lo largo de sus largos trayectos a través de Europa. También, la discusión comenzó progresivamente a centrarse en la posibilidad de que con los buscadores de asilo legítimos estuvieran entrando a Europa islamistas radicales y antiguos combatientes de Daesh que quisieran llevar la Yihad a suelo europeo - clima acentuado por los atentados de París de noviembre de 2015. Más aún, muchas fuerzas políticas europeas, en Alemania y Austria, pero también en otros Estados, apelaban a la incompatibilidad cultural de estos migrantes, que por su acervo musulmán no se integrarían a la sociedad seglar y liberal europea ,lo que para algunos fue probado luego de los eventos relacionados con violencia sexual protagonizados por buscadores de asilo en el año nuevo de 2015 en Colonia, Alemania.

El paquete de medidas que se oficializó luego de arduas negociaciones entre los gobiernos europeos salió a la luz en marzo de 2016. Este era un compendio de medidas a nombre de la Unión que, por

5 De hecho, los intentos por repartirse las cuotas de buscadores de asilo han fracasado, ante la voluntad de muchos de los buscadores de asilo de establecerse en las economías más fuertes de Europa o en los lugares donde ellos perciben que reciben mayores garantías para su residencia, como Alemania, el Reino Unido y Escandinavia (Heffer, 2016). 
paradójico que parezca, se pueden calificar de típicamente westfalianas, puesto que buscaban defender la capacidad de control sobre los flujos migratorios hacia el territorio europeo, mediante la gestión de sus fronteras externas y medidas coercitivas.

Además, la medida de fondo implicó un acuerdo con el gobierno de Recep Tayyip Erodgan en Turquía, el cual puso en profunda duda el compromiso europeo con los derechos de los buscadores de asilo, ante la premura de dar solución a los problemas políticos que se perfilaban como elementos generadores inestabilidad a lo largo de Europa. A grandes rasgos, este paquete de medidas terminaba por traspasarle a Turquía la labor de taponar el flujo de migrantes por asilo hacia Europa -específicamente Grecia-, a cambio de prebendas económicas (6800 millones de euros en 3 años [BBC Mundo, 2016]), la promesa de levantar el visado de turista para los turcos que quisieran ingresar a la Unión y el éxito político más importante para Erdogan, el relanzamiento del proceso de adhesión de Turquía a la Unión Europea, lo cual, en la práctica es de poco interés para el aún presidente turco.

Desde un punto de vista puramente geopolítico - poniendo en el centro la defensa de la soberanía estatal- la decisión de buscar taponar el flujo de migrantes por medio de un proxy puede generar la minimización de diferentes costos de transacción en el largo plazo. En el caso europeo, el acuerdo fue pensado para disminuir las cargas fiscales de los Estados parte, pero también para aminorar los costos políticos de los gobiernos de cada una de las entidades nacionales, ante la amenaza de inestabilidad populista o de poner a prueba el proceso de integración europeo. Sin embargo, en un contexto donde la dinámica de regulación internacional va más allá de la pura coerción material y del poder de seducción político, las decisiones en materia de política pueden acarrear costos en términos de legitimidad para los actores del sistema.

La dinámica internacional actual, compuesta por actores de diferente naturaleza y origen, hace que los actores tradicionales sean señalados cada vez más como responsables de sus actos. En el caso analizado, la Unión Europea y los Estados que la conforman han sido responsabilizados de limitar el ejercicio absoluto de los derechos de los migrantes mediante el acuerdo con Turquía, ante lo que parece ser 
una obstinación por tratar de darle respuesta a sus problemas políticos con mecanismos inspirados en el ejercicio de la soberanía tradicional. Así, hay que comenzar teniendo en cuenta que el pacto europeo con Turquía de marzo de 2016 se hizo con un gobierno sobre el cual recaen varias acusaciones de haber tomado medidas autoritarias en contra de la libertad personal, de opinión y de prensa y que terminaron de confirmarse luego del intento de golpe de Estado en contra de Erdogan en agosto de 2016. Esto implica una aparente contradicción puesto que el acuerdo busca priorizar los derechos de los migrantes sobre cualquier otra cosa (Consejo Europeo, 2016).

Aún más dicientes son las particularidades del acuerdo, con respecto al tratamiento de los migrantes. En el tratado se establece que los Estados europeos devolverán a Turquía a los buscadores de asilo que hayan entrado por su frontera de manera irregular, basándose en que este país, por paradójico que parezca, es un tercer Estado seguro. Como contraprestación, por cada persona devuelta, los Estados europeos se harán responsables de un buscador de asilo que haya llegado a Turquía desde Siria y no haya intentado entrar de manera irregular a Europa, lo que en la práctica genera un intercambio de personas. Para muchos comentaristas esta es una acción que raya con la ilegalidad y que a todas luces no representa el espíritu de la defensa de los derechos humanos.

Por una parte, la devolución raya con el incumplimiento del principio de Non-refoulement consignado en el Convenio de Ginebra. Además, la categorización de Turquía como un Estado seguro para los solicitantes de asilo es el resultado de una decisión política y no de una evaluación objetiva. Al parecer, la Unión Europea ha definido sus intereses de política sobrepasando la evaluación material de las condiciones que determinan la garantía de los derechos fundamentales. Por otra parte, privilegiar el acceso de algunos solicitantes de asilo sobre otros, basándose en la regularidad de su entrada a territorio europeo, termina por negar la protección internacional a personas que la necesitan legítimamente, que a razón del desconocimiento o la imposibilidad de entrar a Europa de otra forma, tuvieron que recurrir a mecanismos no oficiales de ingreso a su territorio. 
Así, de la gestión de la actual crisis migratoria queda por decir que la idea de humanitarismo, tantas veces utilizadas por Europa y Occidente, en general, como un mecanismo de expansión política en otras regiones del mundo, se devuelve contra sí, al quedar su legitimidad en entredicho por la no aplicación objetiva de los derechos humanos frente a los buscadores de asilo. Ante esto la movilización de la sociedad civil organizada ha sido masiva, no solo desde afuera sino también desde adentro. Muchos habitantes de Europa se han tornado en contra de la idea misma de un humanitarismo que parece agotarse ante lo que han tildado de una acción hipócrita y facilista ante la gestión del asunto (Pamuk y Baczynska, 2016). Los resultados se han manifestado desde diferentes esferas del espectro político, traducidos en el fortalecimiento de los movimientos políticos de extrema izquierda y derecha, antieuropeos a todas luces, y de la vuelta al humanitarismo de base, mediante acciones comunales respaldo a los migrantes o de fuerza en contra de ellos. De cualquier forma, desde la esfera extra europea, su legitimidad se desborona, su capacidad de liderazgo en asuntos humanitarios se deshace y la obstinación por mantener el control soberano que se mantiene choca con los derechos de los migrantes. Mientras tanto, la crisis humanitaria continúa sin un fin a la vista.

\section{Conclusión}

Este texto defendió la idea que algunos Estados, obstinados con la defensa acérrima de su capacidad soberana, terminan por dejar de lado parte de sus responsabilidades internacionales como garantes de los derechos humanos. Así, algunos de ellos perderían cierta legitimidad ante actores de la política doméstica e internacional, lo que en el caso europeo puede constituir una suerte de paradoja al ser estos los principales defensores del discurso humanitarista.

La actual oleada de migración por asilo a través de Mediterráneo sirve para ejemplificar lo anterior. Este fenómeno deja prever que la negociación de acuerdos políticos en pro de la defensa de la soberanía estatal dentro de la óptica westfaliana del análisis, termina por permear los derechos de ciertos individuos, como los migrantes, en medio del desarrollo de una crisis con un amplio alcance humanitario. 
De cualquier forma, este tipo de choques demuestran la naturaleza cambiante del sistema internacional contemporáneo. En este permanecen algunas de las lógicas tradicionales westfalianas en las cuales, la seguridad es constantemente asociada con elementos materiales, como el control soberano de las fronteras políticas y la extensión de la autoridad sobre los componentes estatales mínimos como el territorio y la población.

El caso de la migración por asilo sirve también para demostrar cómo las dinámicas de acción transnacionales, encarnadas en regímenes como el de los derechos humanos, permean cada vez la capacidad de acción intergubernamental tradicional. No obstante, el llamado debe ser a dar soluciones basadas en el beneficio de los individuos y no únicamente pensando en los réditos políticos. Lo anterior se basa no en el simple hecho de conseguir un fin humanitario, sino teniendo en cuenta el propósito último de mantener la estabilidad sistémica.

La política entre las naciones, cada vez más influida por fenómenos transnacionales, termina por ser cada vez el objeto de controles colectivos, en medio de esquemas de gobernanza global, y cada vez menos del control soberano de los Estados. No obstante, esta disyuntiva está lejos de ser resuelta y, mientras tanto, el costo humanitario puede seguir incrementándose. Mientras no se logren consensos en este respecto, el entendimiento westfaliano de la seguridad seguirá siendo perjudicial para los derechos humanos.

\section{Referencias}

Abbott K., Robert O. Keohane, Andrew Moravcsik, Anne-Marie Slaughter, and Duncan Snidal (2000) The concept of legalization. International organization, 54 (3), 401-419.

Acnur (2016a). States party to the 1951 Convention relating to the Status of Refugee and the 1967 Protocol. Recuperado de http://www.unhcr.org/ protection/basic/3b73b0d63/states-parties-1951-convention-its-1967-protocol.html

Acnur (2016b). The Scope and content of the principle of non-refoulement. Opinion. Recuperado de http://www.unhcr.org/publications/legal/419c$75 \mathrm{ce} 4 /$ refugee-protection-international-law-scope-content-principle-non-refoulement.html 
Acnur (2016c). Syria regional Refugee Concern. Recuperado de http://data. unhcr.org/syrianrefugees/country.php?id=224

Bade, K. (2008). Migration in European history. Oxford: Blackwell.

BBC Mundo (2016). Turquía y la UE acuerdan un plan para aliviar la crisis de refugiados. Recuperado de http://www.bbc.com/mundo/ noticias/2016/03/160317_acuerdo_turquia_migrantes_refugiados_ue_ps

Bretell, C. y Hollifield, J. (2015) Introduction. En Migration Theory. Talking accross disciplines. London: Routledge

Castles, S. Hein de Haas and Mark J. Mille (2013). The Age of Migration $\left(5^{\text {th }}\right.$ ed.) Basingstoke: Palgrave.

Consejo Europeo (2016). Declaración UE-Turquía, 18 de marzo de 2016. Recuperado de http://www.consilium.europa.eu/es/press/ press-releases/2016/03/18-eu-turkey-statement/

De Haas, H. (2014) Migration Theory. Quo vadis? International migration Institute. University of Oxford. Working paper, 100.

ECOSOC-UN (2015) Trends in International Migration 2015. Recuperado de http:/www.un.org/en/development/desa/population/migration/publications/populationfacts/docs/MigrationPopFacts20154.pdf

Eurostat (2016). Record number of over 1.2 million first time asylum seekers registered in 2015. Recuperado de http://ec.europa.eu/eurostat/documents/2995521/7203832/3-04032016-AP-EN.pdf/

Fulton, D. (2015). Critics Charge That Migration Crisis Is 'A Creation of the West'. Common Dreams. Recuperado de http://www.commondreams. org/news/2015/04/23/critics-charge-migration-crisis-creation-west

Gaffey, C. (2016). Why Niger is West Africa's People-smuggling hub. Newsweek, june 17th. Recuperado de http:/www.newsweek.com/ why-niger-west-africas-people-smuggling-hub-471600

Heffer, G. (2016). Brussels migration chief admits EU has 'failed' after only 272 refugees relocated. Express. Recuperado de http://www.express.co.uk/ news/politics/634671/Europe-refugee-crisis-EU-migration-chief-Dimitris-Avramopoulos-quota-scheme-failed-Syria

Koren, M. (2015). A look back to Europe's worst migration crisis. The Atlantic, September 1. Recuperado de http://www.theatlantic.com/notes/2015/09/ europe-refugee-crisis-war/403315/

Krasner, S. (1982). Strucutral causes and regime consequences: regimes as intervening variables. International Organization, 36 (2), 185-205. 
Krasner, S. (1999). Soverignty: Organized Hipocrisy. London: Priceton University Press.

McConnachie, K. (2014). Governing Refugees. Justice Order and Legal Pluralism. London: Routledge.

Moloney, L. (2013, oct.). EU to Give Italy Extra Funds for Better Immigrant Centers After Lampedusa Disaster. Wall Street Journal. Recuperado de http://www.wsj.com/articles/SB100014240527023033820045791253 90933306978

ONU (2016). Declaración Universal de Derechos Humanos. Recuperado de http://www.un.org/es/documents/udhr/

Pamuk, H. \& Baczynska, G. (2016). EU, Turkey seal deal to return migrants, but is it legal? Or doable? Recuperado de http://www.reuters.com/article/ us-europe-migrants-turkey-davutoglu-idUSKCNOWK0QQ

Sassen, S. (1998). Losing control? Soverignty in the age of Globalization. New York: Columbia University Press

Wihtol de Wenden, C. Schmoll C., Thiollet H. (2015). Migrations en Méditerranée. París: CNRS.

Wihtol de Wenden, C. (2015). El fenómeno migratorio en el siglo XXI. México: FCE.

Williams, E. (2011). Capitalismo y esclavitud. Madrid. Traficantes de sueños 